\title{
Mental disorders and request for psychiatric intervention in an Italian local jail
}

\author{
R. Zoccali, M.R.A. Muscatello, A. Bruno, R. Cambria, L. Cavallaro, G. D'Amico, S. Isgrò, \\ V. Romeo, M. Meduri
}

University Hospital, Messina, Italy

\begin{abstract}
A B S T R A C T
The issue of the prevalence of psychiatric illnesses in Italian prison samples has not received the same attention paid at an international level. The aims of the present study were to evaluate the prevalence of psychiatric disorders diagnosed according to DSM-III-R criteria among an Italian prisoner population, and to examine prisoners' requests for psychiatric intervention in relationship to the presence or absence of different psychiatric disorders. One hundred fortytwo Italian male subjects from the Casa Circondariale of Messina, Italy, were evaluated using the Structured Clinical Interview for DSM-III-R Non-Patient Version - SCID I and SCID II. A very high rate of disorders was found among inmates: $85.2 \%(n=121)$ of the sample were affected by a psychiatric disorder. Of the total sample, $51.4 \%(n=73)$ had requested psychiatric treatment during detention. The detection, diagnosis and treatment of the mentally ill prisoners is a primary goal for a better organization of services and prison settings; screening procedures for evaluating the presence of psychiatric disorders, with the aim to promote differential strategies for the care and rehabilitation of inmates, are needed.
\end{abstract}

\section{Introduction}

Mental health in prison populations is an international problem of increasing proportions, as shown by many studies designed to determine the rate of psychiatric disorders in a prison environment.

While earlier researches and reviews on this issue have generally concluded that major psychiatric disorders, and especially psychoses, were no more frequent in prison samples than in the general populations, (Guze, 1976; Coid, 1984), more recent studies since 1990 have reported clearly higher prevalence rates in prison populations mainly for substance abuse, psychotic disorders and mood disorders on Axis I and for antisocial personality disorder on Axis II of the DSM IV (Coté \& Hodgins, 1990; Herrman, McGorry, Mills, \& Singh, 1991; Koenig, Johnson, Bellard, Denker, \& Frenlon, 1995;Brooke, Taylor, Gunn, \& Maden, 1996; Jordan, Schlenger, Fairbank, \& Caddell, 1996; Taylor, Leese, Williams, Butwell, Daly, \& Larkin, 1998; Baillargeon, Black, Pulvino, \& Dunn, 2000; Gunn, 2000; Hartvig \& Ostberg, 2004). This discrepancy in the results may be due to a number of factors such as different inclusion criteria, selection bias, heterogeneous diagnostic procedures, lack of operational diagnostic criteria and insufficient sample sizes (Teplin, Abram, \& McClelland, 1996; Andersen, 2004). A recent review of 62 surveys conducted in 12 western countries on a total sample of 22,790 prisoners reported that $3.7 \%$ male prisoners were diagnosed with psychotic illnesses, $10 \%$ with major depression and 65\% with personality disorders, while overall $4 \%$ female prisoners were diagnosed with psychotic disorders, $12 \%$ with major depression and $42 \%$ with personality disorders (Fazel \& Danesh, 2002). In Italy, the issue of the prevalence of psychiatric illnesses in prison samples has not 
received the same attention paid at an international level; at the moment, only one cross-sectional study of consecutive male prisoners (224 subjects, corresponding to $22.6 \%$ of a total sample of prisoners) referred for a clinical psychiatric assessment among population $(n=990)$ of the Casa Circondariale of Pavia, has been conducted. The Authors reported an overall prevalence of $19.3 \%$ for one or more mental disorders (substance related disorders were excluded) and the prevalence rates among inmates were $1.3 \%$ for psychoses, $5.4 \%$ for mood disorders, $2.4 \%$ for anxiety disorders, $2.6 \%$ for adjustment disorders, $4.1 \%$ for personality disorders, $3.2 \%$ for personality disorders comorbid with mood disorders, while $0.3 \%$ of the prisoner sample had mental retardation (Carrà, Giacobone, Pozzi, Alecci, \& Barale, 2004).

To the best of our knowledge, epidemiologic screenings on general prison populations do not exist at the present moment in Italian prisons, as the previously cited study has been conducted on a selected sample of prisoners referred to psychiatric services.

The aims of the present studies were:

1. to evaluate the prevalence of psychiatric disorders diagnosed according to DSM-III-R criteria among an Italian prisoner population;

2. to examine prisoners' requests for psychiatric intervention in relationship to the presence or absence of different psychiatric disorders.

\section{Method}

The study was conducted in the period January 2003-June 2004 on the whole population of the Casa Circondariale of Messina.

The total sample consisted of 142 Italian male subjects, mean age $=35.8$ years (range: $20-76$ years; $S D=10.01$ ). All the subjects had been sentenced. Clinical evaluation consisted of the administration of the Structured Clinical Interview for DSM III R NonPatient Version - SCID I and SCID II by a trained psychiatrist. As five subjects did not speak sufficient Italian, in those cases the assessment was conducted with the help of an interpreter. All the subjects provided written informed consent to participate in the study and completed the assessment.

The SCID-I/NP (Fava, Guaraldi, Mazzi, \& Rigatelli, 1993a) assesses selected Axis I psychiatric disorders based on DSM-III-R criteria. Past (lifetime) as well as current presence of individual DSM-III-R disorders can be assessed. In the present study, all the modules were administered with the aim of obtaining a full screening of Axis I psychiatric disorders. Regarding Axis I disorders, six major diagnostic categories were identified: 1) Psychotic Disorders (Schizophrenia and Brief Psychotic Disorders), 2) Mood Disorders (Depressive Disorders, Dysthymic Disorder, Bipolar Disorder), 3) Anxiety Disorders (Generalized Anxiety Disorder, Panic Disorder, Adjustment Disorders, Specific and Social Phobias), 4) Somatoform Disorders, 5) Substance Abuse, and 6) ImpulseControl Disorders.

The Structured Interview for Personality Disorders - SCID II (Fava et al., 1993b) is a semi-structured diagnostic interview for assessing the 11 DSM-III-R Axis II personality disorders plus the Appendix category self-defeating personality disorder. Personality disorder symptoms were rated as either present, subthreshold, or not present on the SCID II. Subthreshold diagnoses were assigned if subjects met one criterion less than required for a full diagnosis of a personality disorder; only the criteria that were definitely present (i.e., scored 2) were counted. All interviews and ratings were conducted by a study investigator with extensive training in SCID administration and scoring.

The data regarding requests for psychiatric intervention were obtained from the medical histories of the sample and from the registers of clinical activity of the psychiatrists working at the prison.

\section{Results}

\subsection{Sample features}

At the time of the study, 9.8\% ( $n=14)$ of the subjects had served less than one year, 33.8\% ( $n=48)$ had served a period between one and five years, 26.8\% $(n=38)$ between six and ten years, $29.6 \%(n=42)$ had served for more than ten years. Regarding the level of education, $8.5 \%$ of the sample were illiterate, $32.4 \%$ had grade $6,52.1 \%$ had less than grade $10,6.3 \%$ had some post-secondary education and only one subject $(0.7 \%)$ was a graduate.

\subsection{Psychiatric disorders}

A very high rate of disorders was found among inmates; at the time of the assessment, $85.2 \%(n=121)$ of the sample $(n=142)$ were affected by a psychiatric disorder; 14 subjects (11.6\%) had only an Axis I disorder, 25 subjects (20.6\%) had an Axis II disorder only, while 68 (56.2\%) suffered from comorbid Axis I and Axis II disorders and 14 (11.6\%) suffered from Axis II subthreshold symptomatology.

These high prevalence rates among inmates were found for the following disorders: first, substance abuse which was the most frequent disorder ( $n=56 ; 46.3 \%)$, anxiety disorders $(n=38 ; 31.4 \%)$, impulse control disorders $(n=22 ; 18.2 \%)$, and affective disorders ( $n=20 ; 16.5 \%)$; less prevalent were psychotic $(n=5 ; 4.1 \%)$ and somatoform disorders $(n=5 ; 4.1 \%)$.

Regarding Axis II disorders, 60.3\% $(n=73)$ an antisocial personality disorder was found, $19.5 \%$ borderline $(n=23), 9.9 \%$ narcissistic $(n=12), 6.6 \%$ istrionic $(n=8), 6.6 \%$ paranoide $(n=8)$, and $5.8 \%$ obsessive compulsive $(n=7)$, dependent $(n=5 ; 4.1 \%)$, avoidant and schizotypic $(n=4 ; 3.3 \%)$, and schizoid personality disorders $(n=1 ; 0.8 \%)$. 
Relative to Axis II subthreshold symptomatology, high prevalence rates were found for borderline $(n=24 ; 19.8 \%)$, paranoid $(n=20$; $16.5 \%)$, self-defeating ( $n=18 ; 14.9 \%)$, antisocial $(n=17 ; 14 \%)$, passive aggressive $(n=16 ; 13.2 \%)$, obsessive $(n=15 ; 12.4 \%)$, narcissistic $(n=11$; $9.1 \%)$, and schizotypic $(n=9 ; 7.4 \%)$, histrionic $(n=6 ; 5 \%)$, dependent $(n=4 ; 3.3 \%)$, avoidant and schizoid personality disorders $(n=3 ; 2.5 \%)$.

\subsection{Requests for psychiatric intervention}

Of the total sample ( $n=142), 51.4 \%(n=73)$ had requested psychiatric treatment during detention; this percentage also includes 9 healthy subjects ( $42.9 \%$ of all healthy subjects, $n=21$ ) who, although not affected by psychiatric disorders, had sought psychiatric treatment.

Of the 121 subjects affected by psychiatric disorders, $52.9 \%(n=64)$ had sought psychiatric consultation, while the remaining $47.1 \%$ had never requested psychiatric treatment.

Considering the kind of psychopathology, specialistic treatment was sought by $71.4 \%(n=10)$ of the subjects affected by Axis I disorders, by $60 \%(n=15)$ of the subjects with DSM IV Axis II disorders, by $47.1 \%(n=32)$ of the subjects with Axis I and II comorbid disorders, and by $50 \%(n=7)$ of the subjects with Axis II subthreshold symptomatology.

Regarding the request for psychiatric consultation, Chi-square test did not show significant differences in the observed distribution in accordance with the type of psychiatric disorder $\left(\chi^{2}=4.126\right.$; g.d.1. $=4$; Sig. $\left.=0.389\right)$.

\section{Discussion}

The present study showed a very high distribution of psychiatric disorders in the examined prison population, with prevalence rates similar to those reported by the previous North-American studies (Cotè \& Hodgins, 1990; Gunn, Maden, \& Swinton, 1991; Jordan et al., 1996) and higher than the results of European studies (Gunn et al., 1991; Maden, Swinton, \& Gunn, 1994) on prisoners on remand (Birmingham, Mason, \& Grubin, 1996).

Considering Axis I disorders, substance abuse was the most frequent disorder with a prevalence rate of $46 \%$, typical of the high distribution usually encountered in prison settings (Andersen, 2004). Although the present study did not differentiate among substances of abuse (alcohol versus other drugs), the data confirmed that the prevalence of substance dependence and abuse is much higher in prison samples than in community populations, as high rates of criminality among drug-dependent subjects are common.

The prevalence of anxiety disorders (31\%) was another significant result; anxiety disorders are recognized as a ubiquitous problem among inmates, with higher rates of Generalized Anxiety Disorder (Koenig et al., 1995). Moreover, the presence of both affective and anxiety morbidity may be related to the very high prevalence of substance abuse and dependence disorders, both inside and outside prisons, as reported by a number of studies (Rounsaville, Weissman, Crits-Cristoph, Wilbert, \& Kleber, 1982; Brooner, King, Kidorf, Schmidt, \& Bigelow, 1997). Finally, the relatively low rates of psychotic disorders in the examined sample (4\%), similar to those rates found in international studies (Andersen, 2004), may be due to the fact that, within the Italian justice system, those subjects with severe mental illnesses such as schizophrenia or other psychotic disorders are readily identified in the first phase of imprisonment and sent to more suitable institutions for evaluation and treatment (Russo \& Salomone 1999).

Regarding Axis II disorders, the prevalence of personality disorders is about three times larger than in the general population, and, as stressed by Rotter, Way, Steinbacher, Sawyer, and Smith (2002), besides the antisocial, other personality disorders are well represented in inmates' samples. Our results showed the high prevalence of antisocial personality disorder (60.3\%), according to previous studies (Andersen, 2004; Fazel \& Danesh, 2002), confirming that antisocial personality disorder is markedly associated with criminal and deviant behaviours. The second most represented personality disorder in the examined sample is borderline, thus confirming the prevalence of personality disorders associated with impulsivity and aggression.

Considering the request for psychiatric treatment, although $85 \%$ of the examined subjects were affected by mental disorders, only the half of the total sample had sought treatment, with no significant differences between Axis I (71.4\%) and Axis II (60\%) disorders. Moreover, the rate of treatment seekers among those subjects with Axis I and Axis II comorbid disorders (47.1\%) was lower than the rate of treatment seekers affected by a psychiatric disorder codified on only one of the two Axes. It can be hypothesized that the presence of an Axis II disorder may reduce insight and, consequently, the request of psychiatric consultation and treatment. Besides those inmates who did not seek psychiatric treatment, although affected by mental disorders (47.1\%), a high rate of healthy subjects (42\%) was treatment seekers. It can be hypothesized that, in prison settings, a number of variables occurs in psychiatric treatment request; on one hand, dissimulation with the aim of obtaining benefits from the assumption of a sick role, such as a special regime, better prison conditions, and the possibility to obtain domiciliary arrest, may induce a number of subjects to spontaneously ask for psychiatric intervention; on the other hand, the lack of insight, the stigma associated with mental illnesses, the fear to be referred to high security psychiatric institutions may induce mentally ill inmates to conceal their symptoms. The detection, diagnosis and treatment of the mentally ill prisoners is a primary goal for a better organization of services and prison settings. Health screening on arrival in the prison system should include screening procedures for evaluating the presence of psychiatric disorders, with the aim to promote differential strategies for the care and rehabilitation of inmates.

\section{References}

Andersen, H. S. (2004). Mental health in prison population. A review-with special emphasis on a study of Danish prisoners on remand. Acta Psychiatrica Scandinavica, 110(Suppl.424), 5-59.

Baillargeon, J., Black, S. A., Pulvino, J., \& Dunn, K. (2000). The disease profile of Texas prison inmates. Annals of Epidemiology, 10(2), 74-80. 
Birmingham, L., Mason, D., \& Grubin, D. (1996). Prevalence of mental disorder in remand prisoners: consecutive case study. British Medical Journal, 313(7071), 1521-1524.

Brooke, D., Taylor, C., Gunn, J., \& Maden, A. (1996). Point prevalence of mental disorder in unconvicted male prisoners in England and Wales. British Medical Journal, 313(7071), 1524-1527.

Brooner, R. K., King, V. L., Kidorf, M., Schmidt, C. W., \& Bigelow, G. E. (1997). Psychiatric and substance comorbidity among treatment-seeking opioid abusers. Archives of General Psychiatry, 54(1), 71-80.

Carrà, G., Giacobone, C., Pozzi, F., Alecci, P., \& Barale, F. (2004). Prevalence of mental disorder and related treatments in a local jail: a 20-month consecutive case study. Epidemiologia E Psichiatria Sociale, 13(1), 47-54.

Coid, J. W. (1984). How many psychiatric patients in prison? British Journal of Psychiatry, 145, 78-86.

Coté, G., \& Hodgins, S. (1990). Co-occurring mental disorders among criminal offenders. Bullettin of American Academy of Psychiatry and the Law, 18(3), 271-281.

Fava, M., Guaraldi, G.P., Mazzi, F., Rigatelli, M. (1993a). SCID Intervista Clinica Strutturata per il DSM-III-R. - Edizione Non Pazienti. Organizzazioni Speciali, Firenze.

Fava, M., Guaraldi, G.P., Mazzi, F., Rigatelli, M. (1993b). Intervista clinica strutturata per la diagnosi di disturbi di personalità, SCID-II. Organizzazioni Speciali, Firenze.

Fazel, S., \& Danesh, J. (2002). Serious mental disorder in 23000 prisoners: a systematic review of 62 surveys. Lancet, 359(9306), 545-550.

Gunn, J. (2000). Future directions for treatment in forensic psychiatry. British Journal of Psychiatry, 176, 332-338.

Gunn, J., Maden, A., \& Swinton, M. (1991). Treatment needs of inmates with psychiatric disorders. British Medical Journal, 303(6798), 338-341.

Guze, S. B. (1976). Criminality and Psychiatric Disorders. New York: Oxford University Press.

Hartvig, P., \& Ostberg, B. (2004). Mental diseases and disorders among inmates in Norwegian prisons. Tidsskr Nor Laegeforen, 124(16), $2091-2093$.

Herman, H., McGorry, P., Mills, J., \& Singh, B. (1991). Hidden severe psychiatric morbidity in sentenced prisoners: an Australian study. American Journal of Psychiatry, $148,236-239$.

Jordan, B. K., Schlenger, W. E., Fairbank, J. A., \& Caddell, J. M. (1996). Prevalence of psychiatric disorders among incarcerated women. II. Convicted felons entering prison. Archives of General Psychiatry, 53(6), 513-519.

Koenig, H. G., Johnson, S., Bellard, J., Denker, M., \& Fenlon, R. (1995). Depression and anxiety disorder among older male inmates at a federal correctional facility. Psychiatric Services, 46(4), 399-401.

Maden, T., Swinton, M., \& Gunn, J. (1994). Psychiatric disorder in women serving a prison sentence. British Journal of Psychiatry, 164, 44-54.

Rotter, M., Way, B., Steinbacher, M., Sawyer, D., \& Smith, H. (2002). Personality disorders in prison: aren't they all antisocial. Psychiatric Quarterly, 73(4), 337-349.

Rounsaville, B. J., Weissman, M. M., Crits-Cristoph, K., Wilber, C., \& Kleber, H. (1982). Diagnosis and symptoms of depression in opiate addicts: course and relationship to treatment outcome. Archives of General Psychiatry, 39(2), 151-156.

Russo, G., \& Salomone, L. (1999). Il malato di mente nel sistema giudiziario. Rassegna Penitenziaria e Criminologica, 2-3, 127 anno III.

Taylor, P. J., Leese, M., Williams, D., Butwell, M., Daly, R., \& Larkin, E. (1998). Mental disorders and violence. A special (high security) hospital study. British Journal of Psychiatry, 172, 218-226.

Teplin, L. A., Abram, K. M., \& McClelland, G. M. (1996). Prevalence of psychiatric disorders among incarcerated women, I: pretrial jail detainees. Archives of General Psychiatry, 53(6), 505-512. 